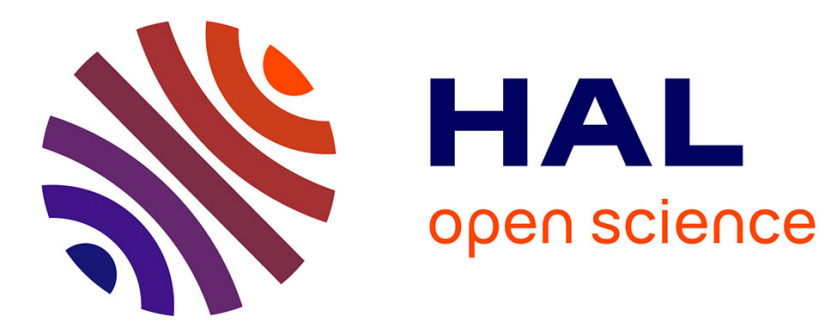

\title{
OPTIMAL AGEING LIMIT OF OIL-IMMERSED TRANSFORMERS IN FLEXIBLE POWER SYSTEMS
}

Ildar Daminov, Marie-Cécile Alvarez-Herault, Raphael Caire, Anton

Prokhorov

\section{- To cite this version:}

Ildar Daminov, Marie-Cécile Alvarez-Herault, Raphael Caire, Anton Prokhorov. OPTIMAL AGEING LIMIT OF OIL-IMMERSED TRANSFORMERS IN FLEXIBLE POWER SYSTEMS. CIRED 2021, Sep 2021, Online, France. hal-03355187

\section{HAL Id: hal-03355187 \\ https://hal.science/hal-03355187}

Submitted on 27 Sep 2021

HAL is a multi-disciplinary open access archive for the deposit and dissemination of scientific research documents, whether they are published or not. The documents may come from teaching and research institutions in France or abroad, or from public or private research centers.
L'archive ouverte pluridisciplinaire HAL, est destinée au dépôt et à la diffusion de documents scientifiques de niveau recherche, publiés ou non, émanant des établissements d'enseignement et de recherche français ou étrangers, des laboratoires publics ou privés. 


\title{
OPTIMAL AGEING LIMIT OF OIL-IMMERSED TRANSFORMERS IN FLEXIBLE POWER SYSTEMS Ildar Daminov ${ }^{1,2}$ *, Marie-Cécile Alvarez-Herault ${ }^{1}$, Raphael Caire ${ }^{1}$, Anton Prokhorov ${ }^{2}$ \\ ${ }^{1}$ Univ. Grenoble Alpes, CNRS, Grenoble INP, G2Elab, 21 Avenue des Martyrs, Grenoble, 38000, France; \\ ${ }^{2}$ Power Engineering School, Tomsk Polytechnic University, 7, Usov street, Tomsk, 634034, Russia; \\ *Email address of corresponding author: daminovib@gmail.com
}

Keywords: TRANSFORMER, AGEING, ENERGY TRANSFER, FLEXIBILITY, CALENDAR LIFE

\begin{abstract}
This paper investigates the choice of optimal ageing limit of transformers in flexible power systems. In contrast to similar studies, the paper considers the remaining calendar life of transformers. Moreover, it is shown that for the same insulation ageing it is possible to transfer a different amount of energy through transformers. Hence, the paper uses a maximal energy transfer as criterion for defining the optimal ageing limit of transformers (both the existing and new ones). Results reveal that the optimal ageing limit for transformers should be equal to the ratio between the remaining insulation life and the remaining calendar life. Moreover, the paper presents the energy transfer through new transformer as function of various ageing limits and different durations of a calendar life. Hence, the choice of ageing limit can differ from traditionally used (normal) ageing limit if system operators consider the ratio between the remaining insulation life of transformers and their remaining calendar life. MATLAB code is available for readers in open access.
\end{abstract}

\section{Introduction}

Nowadays, the energy industry is facing an energy transition towards decarbonized power systems. While many countries upscale renewables to reduce greenhouse gas emissions, their electrical networks face a high stress caused by congestions, voltage instabilities, and harmonics among others. Moreover, the ongoing electrification of heating and transport sector will further increase the electrical load and consequently a stress on a grid infrastructure. While shares of distributed energy resources continue growing fast, electrical networks cannot be reinforced in similar pace. Nevertheless, new opportunities arise for system operators as power systems become flexible as never before. For instance, technologies such as controllable distributed generation, storage, demand side management and dynamic thermal ratings among others allow reducing the stress on electrical networks. Thus, the challenge of system operators in flexible power system is oriented to maximize a grid infrastructure utilization.

The utilization of grid infrastructure in operation planning can be considered by ageing limits. The ageing limit is an integral constraint ensuring that a power equipment operates at variable temperatures whose cumulative effect does not exceed the normative Loss of equipment Life (LoL). For instance, daily LoL of transformer operating at variable temperatures must not exceed LoL if the same transformer would operate at the constant design temperature (usually $98^{\circ} \mathrm{C}$ or $110{ }^{\circ} \mathrm{C}$ ). Such assumption of system operators/researchers ensures that transformers can operate a full design life as predefined by manufacturer. Recent studies [1] testify that the ageing limit of existing transformers can be actually increased higher than normal limit if considering their remaining insulation life. In fact, transformers have significant remaining life since they are operated below the normal ageing limit during the long time. Fig. 1 shows the case when transformer has already operated its design calendar life but a transformer still keeps some resource of insulation allowing to continue its operation.

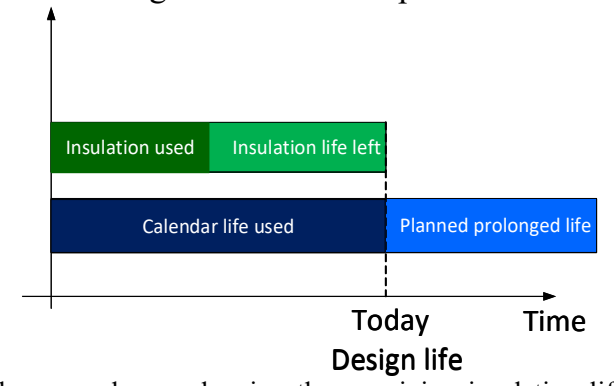

Fig. 1 The general case showing the remaining insulation life and the remaining calendar life of transformers.

Nowadays this situation is relevant in many countries: system operators continue to operate their old transformers beyond the calendar life. As justification of such operation, comprehensive tests conducted by network companies showed that the insulation system and other vital parameters of existing transformers remain in good state even after the end of design life [2]. For instance, in Russia, the mean physical ageing of power (auto-) transformers is only $24 \%$ whereas the calendar life of 50$70 \%$ transformers already overpassed their design life [2]. So far, no study considers the combination of the remaining insulation life and the remaining calendar life.

This paper investigates a choice of optimal ageing limit of transformers while considering various combinations of the remaining insulation life (the green bar in Fig. 1) together with the remaining calendar life (the blue bar in Fig. 1). Note that the exact duration of remaining life (the green bar) is uncertain and for a long time many specialists have been discussing what an exact remaining life of transformer is [3]. This paper assumes that the remaining 
life of insulation is known as given in IEC or IEEE standards [4],[5]. These standards consider a thermal deterioration of the windings insulation subject to hot spot temperatures. Thus, no mechanical, electrical or other deterioration of transformer components is considered here. Nevertheless, this assumption remains realistic since the degradation of winding insulation depends for $98-99 \%$ on current and the initial degree of polymerization (related to a winding insulation) and only for $1-2 \%$ on other factors [6]. Moreover, almost all transformer components except for windings or magnetic core can be replaced in case of their damage [6]. Besides, almost all vital parameters of transformers except for a degree of polymerization and a short circuit impedance can be controlled by conducting the appropriate maintenance programs or by the replacement of damaged elements [6].

The winding insulation represents a resource, which could be utilized with a different energy efficiency. For instance, Fig. 2 shows three arbitrary load profiles of 1000-kVA distribution transformer all having the same LoL at the end of the day (the normal $\mathrm{LoL}=1$ p.u.) but each load profile ensures a different energy transfer. Note that the ambient temperature $\left(\mathrm{T}_{\mathrm{amb}}\right)$ during this day was assumed equal to the rated $\mathrm{T}_{\mathrm{amb}}\left(+20^{\circ} \mathrm{C}\right)$.
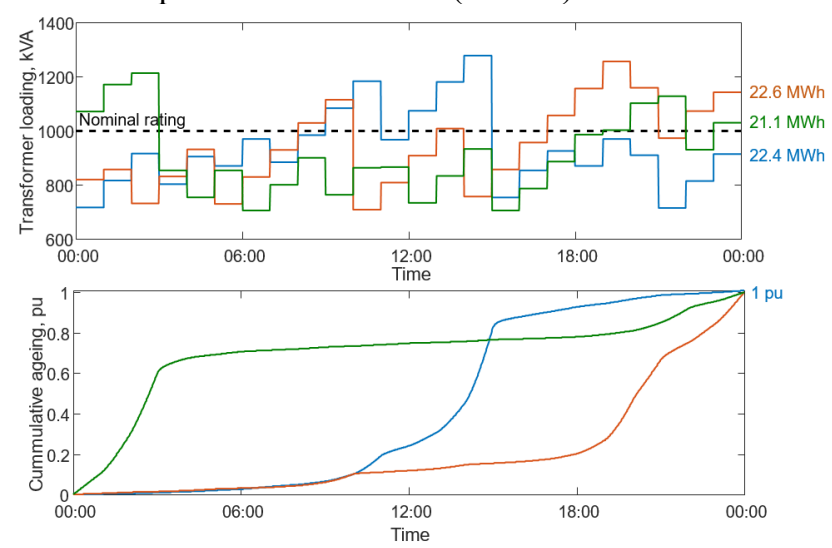

Fig. 2 Arbitrary load profiles having the same LoL (1 p.u.) but different energy transfer. Note that the load profile is given in 1-min resolution but assumed constant over 1-hour step. MATLAB code is available in [7].

Thus, different energy volumes can be transmitted through transformers while using the same insulation resource. Note that flexible power systems allow system operators to modify a load profile. Thus, system operators could increase the energy transfer through transformers without increasing their ageing. To quantify this potential, this paper uses a maximal energy transfer as the criterion for the optimality of the insulation utilization. More details on how the maximal energy transfer of transformers may be calculated are given in the section 2.1 whereas the choice of ageing limit is explained in section 2.2. Note that calculations are supported with the MATLAB code which is available in [7].

The main contribution of this paper is:

- It is shown that ageing limit should be chosen with consideration of a ratio between the remaining insulation life and the remaining calendar life.

\section{Methodology}

The reader can address the section 2.1 to see what the maximal energy transfer of transformers is. In section 2.2 the reader can find a discussion on optimal ageing limit.

\subsection{Optimal energy transfer}

As it was mentioned in the introduction, different energy transfers can be ensured while consuming the same insulation resource. Thus, it is logical to firstly answer the question what is the optimal utilization of insulation resource maximizing the energy transfer? To know the answer the reader should address to Fig. 3.
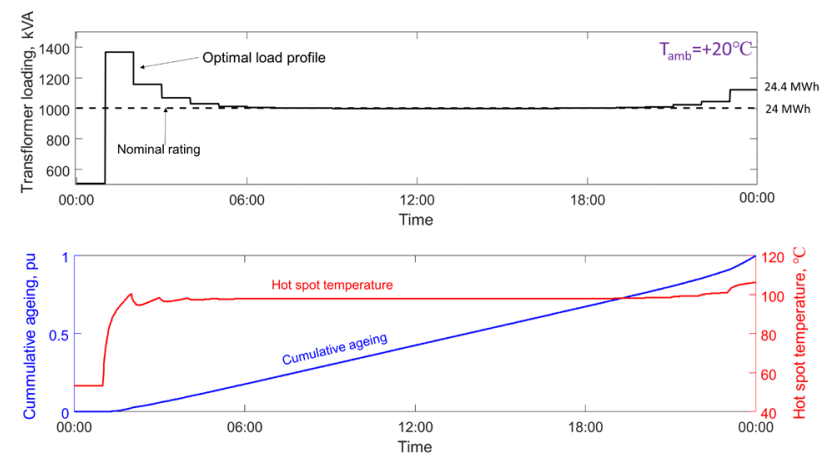

Fig. 3 Top figure: optimal load profile (the black line) ensuring the highest energy transfer and thus the optimal utilization of insulation. Bottom figure: a cumulative ageing (the blue line) and a hot spot temperature (the red line), corresponding to the black line [7].

To obtain the optimal load profile (the black line) the optimization problem was formulated and then solved [7] in MATLAB (using a problem-based formulation [8] and the solver fmincon with SQP algorithm). The objective function was set as a maximization of energy transfer through a distribution transformer for one day. The constraints in the optimization problem were defined by the normal cyclic limits on winding $\left(120{ }^{\circ} \mathrm{C}\right)$ and oil temperatures $\left(105{ }^{\circ} \mathrm{C}\right)$ as well as the cumulative ageing (1 p.u.). Corresponding thermal constraints were calculated in accordance with IEC 60076-7 (see the annex E in IEC standard [4]). The full mathematical formulation of such optimization problem is given in [9]. To compare the optimal load profile with arbitrary load profiles in Fig. 2 $\mathrm{T}_{\text {amb }}$ was kept the same i.e. $+20^{\circ} \mathrm{C}$.

The reader can note that the optimal load profile transfers 24.36 MWh during the day. As expected the optimal energy transfer is higher than the energy transfer of arbitrary load profiles from Fig. 2 (21.1 - 22.6 MWh). However, the surprising observation is that the optimal transfer is higher for $0.36 \mathrm{MWh}$ than the energy transfer (24 MWh) at the rated conditions: the nominal power $(1000 \mathrm{kVA})$ and $\mathrm{T}_{\mathrm{amb}}\left(+20^{\circ} \mathrm{C}\right)$. Such better energy transfer becomes physically possible due to the thermal inertia of transformer (see [9] for the details). Briefly, due to thermal inertias of windings their temperature changes slower than a current change. Therefore, it is possible to transfer a little bit more energy while the temperature is still reaching its steady-state value. 

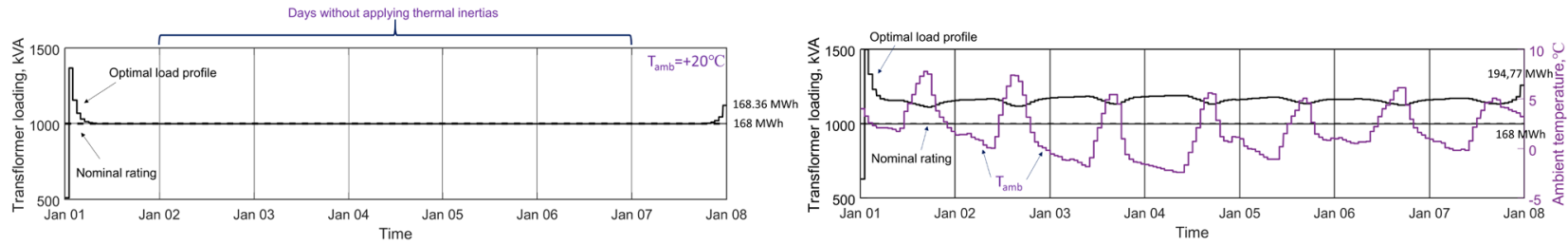

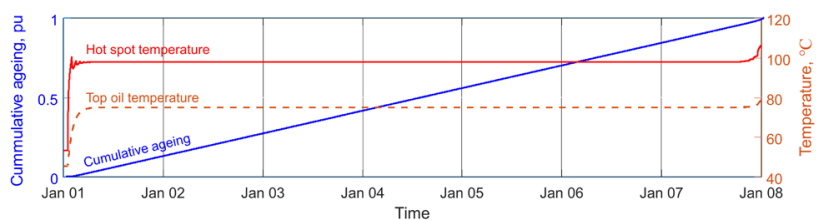

(a)

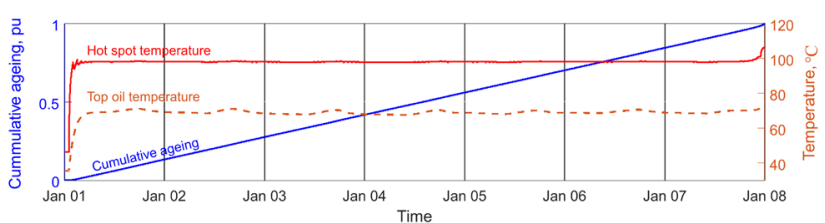

(b)

Fig. 4 Optimized load profile (the black line) ensuring the highest energy transfer for 1 week at: (a) rated $\mathrm{T}_{\mathrm{amb}}=+20{ }^{\circ} \mathrm{C}$ and (b) real $\mathrm{T}_{\mathrm{amb}}$ in Grenoble, France (01.01.2019-07.01.2019) .MATLAB code is available in [7]

Another important observation in Fig. 3 is that the solution of the optimization problem is prone to keep the rated hot-spot temperature $\left(98{ }^{\circ} \mathrm{C}\right)$ most of the time. Therefore, the insulation resource is consumed at the rated speed also known as Ageing Acceleration Factor (AAF) [5]. As a consequence, the optimal LoL curve (the blue line) increases gradually and not as LoL curves in the Fig. 2. Hence, we deduce the answer for the question posed earlier: the optimal utilisation of insulation resource (from the point of view of energy transfer) happens if the insulation resource is equally consumed at each time moment i.e. $\mathrm{AAF}=$ const (if ignoring thermal inertias).

The reader can pose the question if thermal inertias provide additional energy transfer why they are ignored? The answer is that despite their advantage, thermal inertias are applied in the optimal solution only in the beginning and in the end of the studied horizon. For the rest of studied horizon the optimal solution keeps a rated hot spot temperature. This is especially evident if we increase a horizon of optimization problem from one day to one week (see Fig. 4a above). The reader can see that during January 2-6 the optimal loading does not depend on thermal inertias (temperatures and loading are constant). Moreover, if reader would compare the energy transfer for horizons of 1 day and 1 week then it is appeared that thermal inertias ensure the same increment of energy transfer $(0.36 \mathrm{MWh})$ over the energy transfer at nominal conditions. Hence, thermal inertias has limited impact especially if a horizon becomes longer (the energy transfer by thermal inertias remains the same while a total energy transfer increases).

The reader can notice that in Fig. $4 \mathrm{a}$ the constant $\mathrm{T}_{\mathrm{amb}}$ $\left(+20{ }^{\circ} \mathrm{C}\right)$ was assumed over the week. Even if real $\mathrm{T}_{\mathrm{amb}}$ [10] is considered (see Fig. 4b), that does not affect the optimal thermal regime of transformer (bottom Fig. 4a and bottom Fig. $4 \mathrm{~b}$ are almost the same). However, we can see that optimal loadings become variable at variable $\mathrm{T}_{\mathrm{amb}}$ (Fig. 4b) whereas at constant $\mathrm{T}_{\mathrm{amb}}$ they remain constant (Fig. 4a). This happens because the optimal solution tends to keep the same profile of the hot spot temperature but due to variability of $\mathrm{T}_{\mathrm{amb}}$ it is necessary to adjust the load profile. Since the load is adjusted, the energy transfer becomes even higher (194, $77 \mathrm{MWh})$ than if transformer would operate at nominal rating (168 MWh). The reader can see [9] for more details on the impact of climates on the energy transfer of transformers. However, the most important observation in Fig. 4 is that for different $T_{a m b}$ the shape of optimal hot spot temperatures remains the same and the optimal top oil temperature fluctuates negligibly. This confirms the statement that a maximal energy transfer tends to the same thermal conditions even under various $\mathrm{T}_{\mathrm{amb}}$ (a constant $+20^{\circ} \mathrm{C}$ in Fig. $4 \mathrm{a}$ versus the range $\left[-2.5^{\circ} \mathrm{C}\right.$ : $\left.+8{ }^{\circ} \mathrm{C}\right]$ in Fig. 4 b). To say precisely: such conclusion is true for $\mathrm{T}_{\mathrm{amb}}$ ranges where a hot spot temperature remains a limiting factor of loadings (see $T_{a m b}$ ranges in [11] and [9] for an example where a current is a limiting factor).

Thus, for arbitrary $T_{a m b}$ profile it is possible to calculate approximated energy transfer without solving an optimization problem. To do that, it is necessary reproduce the profile of rated hot spot temperature over the given horizon. For doing this, the reader can use the algorithm presented in [11]. Briefly, the principle of this algorithm consists in adjusting a transformer load for each value of $\mathrm{T}_{\mathrm{amb}}$ until the rated hot spot temperature is reached. This algorithm can be especially useful for long horizons because for long intervals (months and years), the optimization problem may become intractable [12]. Briefly, this happens due to the high time resolution of data required by IEC thermal model. The high time resolution at long intervals leads to significant rise of state variables and constraints in optimization problem [12]. Thus, such algorithm can be used at long horizons to obtain a feasible solution close to the optimal maximum.

\subsection{Optimal ageing limit}

In previous section the ageing limit was always equal to 1 p.u. at short-term horizons (a day or a week). As it was mentioned earlier, recent studies suggest to increase the ageing limit higher than 1 p.u at short-term horizons. For the first glance, if the ageing limit would be increased then the energy transfer should increase also (since the mathematical constraint in the optimization problem becomes less restrictive). However, the not-evident result, is that an increasing of ageing limit can in fact decrease the energy transfer over the remaining calendar life (as the 
latter one is omitted in similar studies or equal to the design life). Oppositely, the reduced ageing limit can increase the energy transfer through transformers over their remaining calendar life. The increasing/ decreasing of ageing limit at short-term horizons should depend on the specific ratio between the remaining insulation life and the remaining calendar life. Fig. 5 shows situations where decision on ageing limit increasing/decreasing is different.

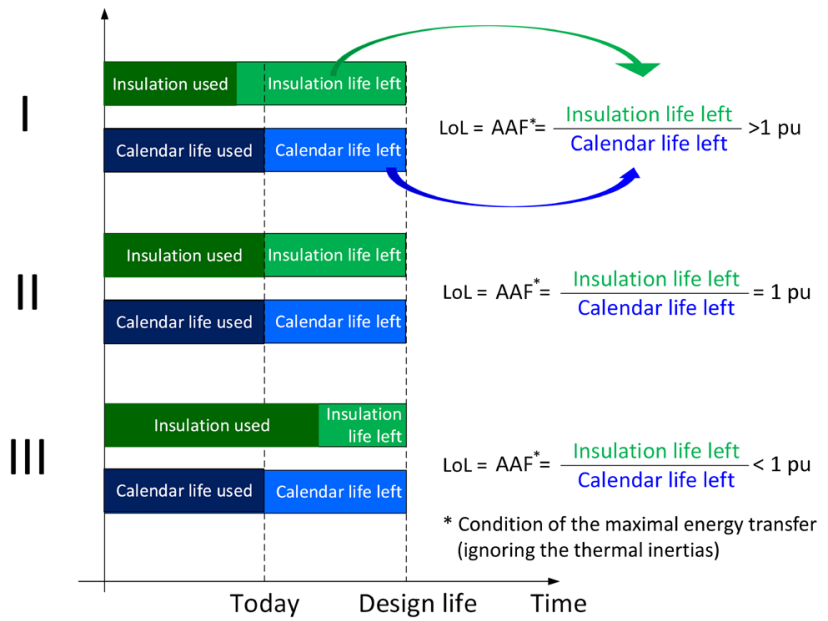

Fig. 5 Situations when various ageing limits (LoL in the figure) maximize the energy transfer at the remaining calendar life of transformer

First case corresponds to the situation when the used insulation life (the dark green bar) is less than the used calendar life of transformer (the dark blue bar). This is a typical example of network transformers located at primary substations [6]. As rule of thumb, primary substations have two transformers, each able to carry a substation load alone in N-1 mode. Hence, such transformers are usually lightly loaded in $\mathrm{N}$ mode i.e. most of the time. Light load often coincidences with $\mathrm{T}_{\mathrm{amb}}$ below the rated $\mathrm{T}_{\mathrm{amb}}\left(+20^{\circ} \mathrm{C}\right)$ of transformers. This leads to small or even negligible ageing of insulation resource. For such transformers, it can be beneficial to increase the ageing limit but the remaining calendar life must be considered.

Second case from Fig. 5 corresponds to the situation when actual insulation ageing is equal (or close) to the time of transformer operation. Such situation can happen with step-up (block) transformer of thermal power plants [6], working as baseload generation. Such transformers, in contrast to network transformers, are more often loaded close to their nominal rating since baseload power plant should operate at maximal available capacity. The normal ageing limit should be preferred for such situations.

Third case from Fig. 5 corresponds to situation when the actual insulation life exceeds the time of the transformer operation. Among possible reasons this can happen if moisture and/or oxygen content in insulation-oil system overpasses their admissible limits. For example, free-breathing transformers (in contrast to sealed transformers) are more exposed to moisture and oxygen ingress from atmosphere [3]. This accelerates the insulation ageing of transformer even at rated hot spot temperature. Harmonics can also significantly accelerate the deterioration of winding insulation even if temperature gauges never achieve alarm set points [13]. As a result, the insulation life of transformer is reduced faster than its calendar life. In such situation, decreasing of ageing limit can prolong a time of transformer operation.

Let us assign specific numbers (Table 1) to green and blue bars from Fig. 5 and find an energy transfer at remaining calendar life for different ageing limits. The $\mathrm{T}_{\mathrm{amb}}+20{ }^{\circ} \mathrm{C}$ will be held constant. Fig. 6 shows calculated energy transfers as a function of ageing limits.

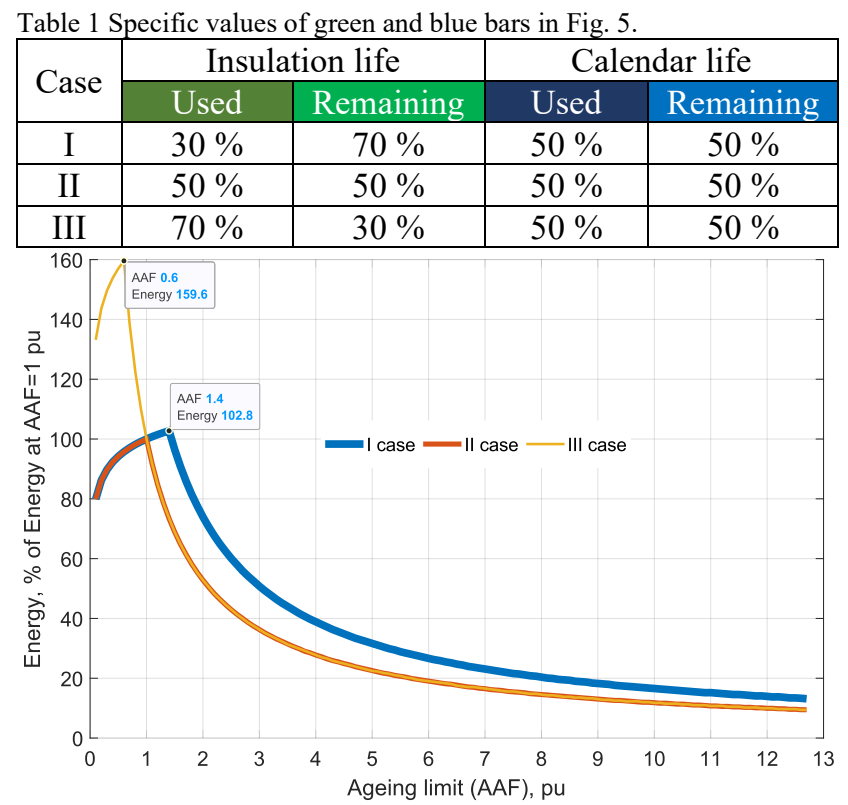

Fig. 6 Energy transfer as a function of ageing limits for 3 cases [5]. \% on $\mathrm{y}$-axis are related to each case alone and not intended for a comparison between cases.

Optimal energy transfers are achieved at low (case III), normal (case II) and high ageing limit (case I). Note that in I case the optimal ageing limit increased for $40 \%(1.4$ p.u.), but the energy transfer increased for $2.8 \%$ only. Whereas in III case the optimal ageing limit reduced down for $40 \%$ (0.6 p.u.) but the energy transfer increased by $59,6 \%$. Thus, it seems that a reduced ageing limit can be relatively beneficial than increased ageing limits. This result can be explained by the exponential dependency between loadings and AAF (see [11] for more details).

Fig. 5 assumed that a calendar life (a blue bar) is equal to a transformer design life. However, this is not always the case in practice. In fact, a calendar life of existing transformers can last longer than their design life (Fig. 1.) The same situation happens with new transformers(Fig. 7).

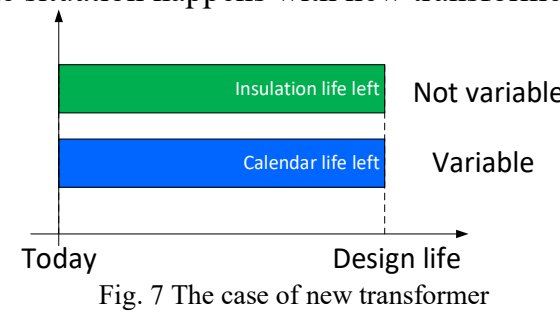

Fig. 7 The case of new transformer 
Two facts should be highlighted for the case of new transformer: (1) the insulation resource of winding cannot be extended for cost-efficient approach so far. Therefore, a green bar is assumed constant (i.e. not variable). However, (2) a calendar life (the blue bar) can have any duration depending on planning priorities of network company. Thus, a maximal energy transfer depends on the calendar life (the blue bar) and ageing limit. Fig. 8 shows an energy transfer by varying a calendar life and an ageing limit.

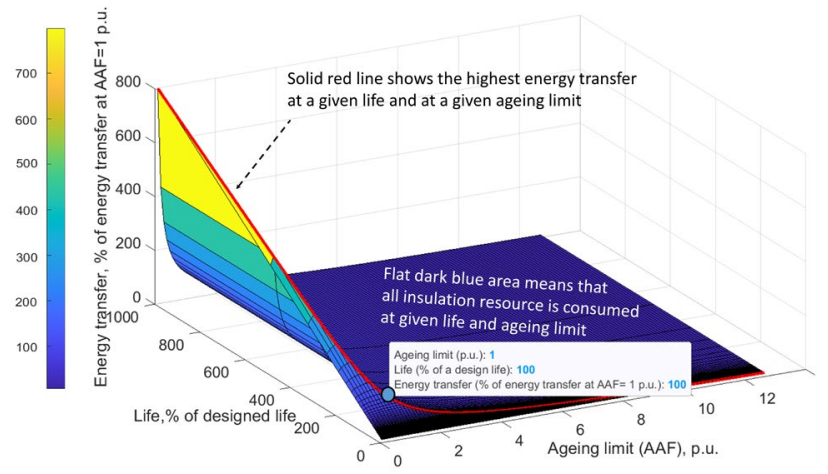

Fig. 8 Dependency: an ageing limit-a remaining calendar life-a maxima energy transfer. MATLAB code is available in [7]

From Fig. 8 we see that low ageing limits allow transformers operate longer and transfer up to 8 times more energy than at normal ageing limit. Despite these benefits, we do not believe that operation at ageing limit below 0.5 p.u. is practically reasonable for a maximization of energy transfer. At such low ageing limits, transformer should operate about 60-300 years. For such very long horizons, it is quite probable that advances in transformer manufacturing would make operation of "old" transformers economically inefficient e.g. due to high losses at such long periods. However, operation at ageing limits between 0.5 p.u. and 1 p.u. (i.e. up to 60 years) may represent a practical value. It may be also beneficial to operate transformers at ageing limit $>1$ p.u. if remaining insulation resource is sufficient. Note that the maximal AAF is limited by the limit of hot spot temperatures (120 ${ }^{\circ} \mathrm{C}$ for normal cyclic loadings). For $120{ }^{\circ} \mathrm{C}$, the ageing limit is equal to 12.7 p.u. for Kraft paper and 2.7 p.u. for thermally-upgraded paper. Anyway, high ageing limits lead to small increment in energy transfer as it is shown in Fig. 6. Besides, high winding temperatures may cause a transformer failure. More investigations based on economic, reliability studies are needed.

\section{Conclusion}

The paper shows that the optimal ageing limit for short-term horizons should be chosen with consideration of the ratio between the remaining insulation life and calendar life. Otherwise, system operators may underuse the insulation resource of windings at the remaining calendar life (omitted in other studies) or even damage transformers when situation requires to reduce the ageing limit. The paper generalizes main situations with different ratios (green and blue bars) and suggests which ageing limit should be preferred. Moreover, the paper explains how utilize the winding insulation resource to maximize energy transfers. Specifically, by solving the optimization problems for 1 day and 1 week we revealed that maximal energy transfer tends to particular thermal regime not depending on $\mathrm{T}_{\mathrm{amb}}$ (if hot spot temperature is a limiting factor of loadings). Furthermore, the paper shows that thermal inertias have a limited impact on the maximal energy transfer so they can be ignored. The case of new transformer was studied by varying its calendar life and ageing limits. It seems that ageing limits between 0.5 p.u. and 1 p.u. could have a practical value in operation planning and should be studied in more details. It is also shown that a low ageing limit has relatively higher increment of energy transfer in \% versus increased ageing limits. Finally, MATLAB code is provided in open access.

\section{Acknowledgements}

We deeply appreciate Conference des Grandes Ecoles, who first supported our research and laid the ground for its further development. The research is also funded from Tomsk Polytechnic University Competitiveness Enhancement Program grant. Authors thank IDEX for funding Ildar DAMINOV travel grant. We gratefully appreciate the funding from Grenoble INP received within ATER position of Ildar DAMINOV. We thank Egor GLADKIKH, a founder of TOPPLAN start-up for his help with financing the Ph.D. thesis. Author thank MeteoBlue for providing data of ambient temperature in Grenoble.

\section{References}

1 Viafora, N., Holboll, J., Kazmi, S.H.H., Olesen, T.H., Sorensen, T.S.: 'Load dispatch optimization using dynamic rating and optimal lifetime utilization of transformers', in '2019 IEEE Milan PowerTech'. (2019)

2 Ministry of Energy: 'Technical state of electric power facilities (physical wear and tear)', https://minenergo.gov.ru/node/11201, accessed February 2021 [In Russian]

3 Feng, D.: 'Life expectancy invesitgation of transmission power transformers'. 2013

4 IEC: 'Loading guide for oil-immersed power transformers' (2018)

5 IEEE: 'Guide for Loading Mineral- Oil-Immersed Transformers and Step-Voltage Regulators' (2012)

6 Maiorov, A., Lvov, M., Lvov, Y., Komarov, V., B, E.: 'Power transformers and autotransfrormers of electrical network life time prediction'Energetik, 2018. [In Russian]

7 Daminov, I.: 'MATLAB-code', https://github.com/IldarDaminov/MATLAB-code-for-CIRED-paper, accessed February 2021

8 'Problem-Based Optimization Workflow', https://fr.mathworks.com/help/optim/ug/problem-based-workflow.html, accessed February 2021

9 Daminov, I., Prokhorov, A., Caire, R., Alvarez-Herault, M.: 'Energy limit of oil-immersed transformers: A concept and its application in different climate conditions'IET Gener. Transm. Distrib., 2021, 15.

10 MeteoBlue: 'Ambient temperature history for Grenoble region', https://www.meteoblue.com/en/weather/archive/export/grenoble_franc e_3014728

11Daminov, I., Prokhorov, A., Caire, R., Alvarez-Herault, M.-C.: 'Assessment of dynamic transformer rating, considering current and temperature limitations'Int. J. Electr. Power Energy Syst., 2021, 129.

12 Daminov, I., Rigo-Mariani, R., Caire, R., Prokhorov, A., AlvarezHerault, M.-C.: 'Demand Response coupled with Dynamic Thermal Rating for increased transformer reserve and lifetime' Energies, 2021.

13 Sparling, B.: 'Managing existing transformers in the grid transition'Transformers, 2020, 7, (2). 